\title{
USERS ACCEPTANCE ON MIXED REALITY TECHNOLOGY
}

\author{
Rasimah Che Mohd Yusoff, Universiti Teknologi Malaysia, rasimah@ic.utm.my \\ Roslina Ibrahim, Universiti Teknologi Malaysia, lina@ic.utm.my \\ Halimah Badioze Zaman, Universiti Kebangsaan Malaysia, hbz@ftsm.ukm.my \\ Azlina Ahmad, Universiti Kebangsaan Malaysia, aa@ftsm.ukm.my \\ Syazani Suhaifi, Universiti Multimedia Malaysia, syazani2902@gmail.com
}

\begin{abstract}
User studies need to be perform on the new technology such as Mixed reality (MR) before it reach maturity. In this paper we would like to reveal the study that has been done to determine users' perception and acceptance on the mixed reality prototype, named Mixed Reality Regenerative Concept (MRRC). The aim of MRRC is to increase users understanding on regenerative concept and tissue engineering. The participants consisted of 37 volunteers from $2^{\text {nd }}$ and $3^{\text {rd }}$ year Biomedical Science students who have never experienced with mixed reality technology. We used constructs personal innovativeness, perceived enjoyment, perceived ease of use, perceived usefulness and intention to use to evaluate respondents' acceptance. Results showed that perceived usefulness was the most important factors to determine the intention to use of mixed reality technology compared to perceived enjoyment and perceived ease of use. However students showed high willingness to use the technology in the future.
\end{abstract}

Keywords: perceptions, technology acceptance, mixed reality

\section{INTRODUCTION}

Mixed reality (MR) is amongst the potential technologies that has gained attention and popularity recently. This is because it is realistic, authentic, engaging and fun [32]. In education setting, Dede claimed that properly designed virtual environment with MR or AR (Augmented Reality) interface can foster neomillenial learning style through physical and sensory immersion [5]. The implementation of this new technology in teaching and learning can increase students' motivation.

Actually, MR technology is not new because it has been invented almost 50 years ago. But, the use of MR applications was more towards laboratory research. Now, it is widely used by people in various settings such as entertainment, education and training [2].

Azuma et al. [31] addressed that since many research systems have been demonstrated but only few have matured beyond lab-based prototypes, social acceptance issues should be addressed before they are widely accepted. Even though there are a lot of advantages of MR that have been promoted, it is appropriate to understand users' perceptions towards this technology before further implementations.

Thus, a better understanding on end-users' perceptions towards the MR system is needed. The feedback can be used as a guideline for developers and administrators who are considering implementing the system using MR technology in future.

The objective of the study is to investigate users' perceptions towards mixed reality application. We developed mixed reality protototype, named Mixed Reality Regenerative Concept (MRRC) as a case study. In this study, we would like to answer the following research questions:

i) What factors or constructs can be used to determine users' acceptance on MR application?

ii) What are the causal relationships between the constructs?

iii) Which construct(s) affect(s) the intention to use of the MRRC?

The next section is about related work mainly in technology acceptance and MR technology. This is followed by by theoretical framework, methodology and results. The final section include a discussion of the findings, limitations of the study, and some directions for future research. 


\section{Issues in Information Systems \\ Volume XII, No. 1, pp. 194-205, 2011}

\section{RELATED WORK}

\section{Mixed Reality Technology}

The AR technology is not new since the first AR interface was developed by Sutherland in the 1960's [34]. But it was not until the early 1990s when the term "augmented reality" was coined by Caudell and Mizell. They were researchers at Boeing Corporation that dedicated most of their time developing experimental augmented reality systems to facilitate workers putting together wiring harnesses in planes [4].

There are a few common accepted definitions of AR or MR. Brett explained that AR interface combines aspects of virtual reality and real-world environment by providing a person a chance to view one or more virtual 3D objects in real-world space[1]. According to Kondo, mixed reality is similar to virtual reality technology that combines interactive three-dimensional computer graphics with the real world[35].

However, the definition by Ronald Azuma is widely accepted as a 'benchmark' to describe AR or MR [30]. Azuma described the environment characteristics of AR: it combines real and virtual objects, it is interactive in real-time, and it is registered in 4D (3 dimensions of space and one dimension of time).

Milgram described a reality-virtuality continuum that spans from the real environment to a pure virtual environment [25]. In between, there is MR that consists of Augmented Reality (closer to the real environment) and Augmented Virtuality (closer to the virtual environment) as shown in Figure 1.

Figure 1. Milgram Reality-Virtuality Continuum

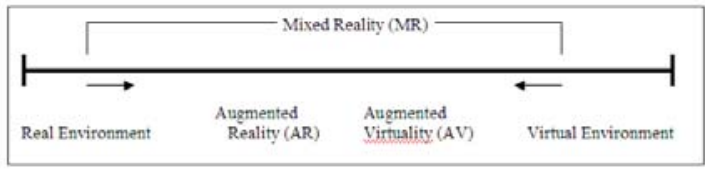

With those characteristics, the experience offered by MR is different from other technologies. This is because it can support the seamless interaction between the real and virtual environments, allowing the use of a tangible interface metaphor for object manipulation and the ability to change smoothly between reality and virtuality. In the future, these applications are likely to become common in various application fields like education, medicine, military, entertainment and industry [31].

Nowadays, more heterogeneous group of users are using AR or MR applications. The users are changing from developers and researchers to wide variety of consumers. In order to make a successful introduction of MR applications to the consumer markets, more attention needs to be paid to the usability of the applications. Besides that, performance studies as well as ergonomics and ease of use are important future research issues.[21].

It is important to understand the users' acceptance because the success or failure of a system depends on how well people like the system, how easy it is to use, and the system's effectiveness [2]. In a more common outcome is that if a system is not liked by users, it simply will not be used, and the money spent on its development will be wasted.

\section{Technology Acceptance}

Technology acceptance can be defined as how people perceive, accept, and adopt some technology to use [19]. Technology acceptance models are used to explain how users come to use or accept a specific technology. These models have their origins in the disciplines of psychology, information systems, and sociology. Many models to measure end-users' acceptance of a new technology have been suggested such as Theory of Reasoned Action (TRA), Theory of Planned Behaviour (TPB), Innovation Diffusion Theory (IDT) and Unified Theory of Acceptance and Use of Technology (UTAUT) [36]. 
Volume XII, No. 1, pp. 194-205, 2011

However, Technology Acceptance Model (TAM) has become one of the most widely used and empirically validated models within information system research [37][26]. It has been applied to different technologies and has been tested in different contexts. According to Lisa, one of the assumptions of research performed using TAM is that usage of the technology is voluntary [17]. According to Davis, the goal of TAM is "to provide an explanation of the determinants of computer acceptance that is generally capable of explaining user behaviour across a broad range of end-user computing technologies and user populations, while at the same time being both parsimonious and theoretically justified" [9]. Figure 2 shows the basis of TAM by Davis [10].

Figure 2. Technology Acceptance Model (TAM)

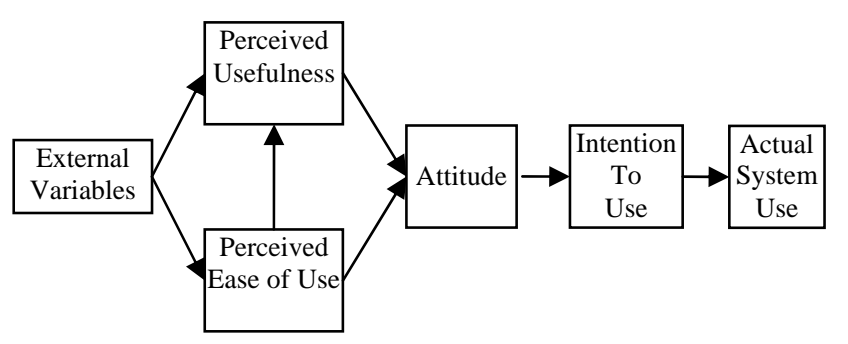

Since various technologies have been used, researchers normally will emerge the basic TAM model with a few factors that are suitable with the system they want to test. Determining the factors or constructs associated with user acceptance of new software systems has been an important research stream in the field of information systems for many years [6]. Constructs or determinants are weighted factors used to explain the acceptance and use of the technology. Table 1 shows some of the previous research that used TAM model and its extents with some related constructs or variables.

Table 1. Extended TAM

\begin{tabular}{ll} 
Context & Extended Constructs \\
\hline $\begin{array}{l}\text { Edutainment game for } \\
\text { secondary students[15] }\end{array}$ & $\begin{array}{l}\text { Gender, games experience, } \\
\text { learning opportunity }\end{array}$ \\
$\begin{array}{l}\text { Virtual reality for } \\
\text { treatment of mental } \\
\text { health [20] }\end{array}$ & $\begin{array}{l}\text { External control, } \\
\text { computers anxiety, } \\
\text { Intrinsic motivation }\end{array}$ \\
$\begin{array}{l}\text { E-learning for Chinese } \\
\text { managers participating } \\
\text { in an Executive MBA } \\
\text { program[11] }\end{array}$ & $\begin{array}{l}\text { Personal innovitiveness, } \\
\text { computer anxiety }\end{array}$ \\
$\begin{array}{l}\text { LEGO programming } \\
\text { for robot [6] }\end{array}$ & Perceived enjoyment \\
$\begin{array}{l}\text { Various online games } \\
\text { [7] }\end{array}$ & Flow, social, critical mass
\end{tabular}




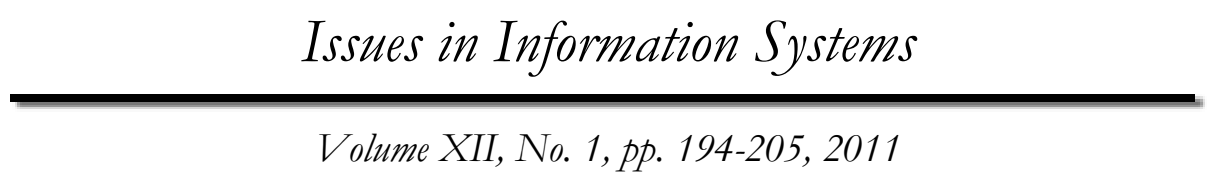

\section{Technology Acceptance of Mixed Reality Technology}

MR and AR are relatively new technologies considering commercially and publicly available applications. As a research field, it has existed for almost five decades with applications in diverse domains such as medicine, military, entertainment, technical support and education[33]. MR systems are expensive to design and to be developed. History has shown that as new technologies, even before maturing and succeeding in penetration and acceptance in our daily lives, there is a need to carry out user studies to understand users' perceptions of usability and usefulness of such technologies as early as possible to avoid expensive remedial work later [38].

A new technology is considered to have been integrated successfully into an organisation or workplace when it is actually used by the people it is intended for. There are many instances where technology has been introduced in organisations and then it has not been used for a number of reasons. One major contributor to the lack of usage is certainly due to the usability of the product or system itself. Another issue is how well the system operates together with the users in a social context. Are the users interested and do they see the same potential in the system as the people (management) who decide to introduce it in the organisation? Davis described two important factors that influence the acceptance of new technology in organization [10]. The perceived usefulness of a system and the perceived ease of use; both influence the attitude towards the system and hence the users' behaviour when interacting with the system, as well as the actual use of the system.

Users will accept the system that they consider as useful even though it is perceived as harder to use. So, it is important to understand users' acceptance because the success or failure of a system depends on how well people like the system, how easy it is to use, and the system's effectiveness [2]. In a more common outcome is that, if a system is not liked by users, it simply will not be used, and the money spent on its development will be wasted. For an AR or MR system, this means that even though the system may be awkward or bulky (head-mounted), if the applications are good and useful enough, the users will accept it. Equally, if the AR system is not perceived as useful, then the system will not be used, even though it may be easy to use or people enjoy using it [33].

\section{THEORETICAL FRAMEWORK AND HYPOTHESES}

In this study, for the development of research instrument, we used the constructs in generic acceptance model, which are perceived usefulness, perceived ease of use, and the intention to use. Besides those basic factors of TAM, we were also interested to know the respondents' response towards new technology and respondents' experience while interacting with the MR prototype in influencing the intention to use of MR application.

A lot of researches interested to know how users' personality might influence their behaviours. One of the pioneer theories is Rogers' Innovation Diffusion Theory (IDT) [28]. IDT suggests that users' personality differences can potentially influence how users form their intentions to perform behaviours.

By exploring the technology adoption stages, Rogers revealed that: (i) users with higher levels of personal innovativeness are more prone to have more favourable attitude towards new technologies; and (ii) highly innovative users are more willing to embrace new technologies into their daily routine by coping with the uncertainty of innovative technologies. Hae et al. in their study on online travel shopping indicated that innovativeness influenced traveller's online shopping behaviour [14]. Similarly, Farzana [12], O’Cass and Fenech [24] suggested that highly innovative web users are more likely to develop more positive attitude towards new technologies. Since personal innovativeness will influence the adoption of new technology to a great extent, we consider it as one of the important constructs that will affect users' acceptance on MR technology. For this study, it is appropriate to test the personal innovativeness in IT with perceived ease of use of using MRRC.

The aim of the system or prototype of MRRC is to increase users' understanding on regenerative concepts. The use of MR technology will give users different experience since it is engaging, exciting, and fun. So, the prototype of MRRC can be considered as partly utilitarian and hedonic system. Enjoyment is one of the constructs that is commonly used to determine the acceptance of the dual-system [36][6]. In this study, enjoyment is one of the important constructs that might affect the acceptance towards MR technology. The previous study claimed that perceived enjoyment has no direct influence on intention to use, but that it can influence on the ease of use and 
Volume XII, No. 1, pp. 194-205, 2011

usefulness [22][29][36]. Therefore, in this study, we would like to know whether enjoyment is positively related to intention to use the MR system.

Prior research indicated that perceived usefulness is an important indicator for technology acceptance [9][36]. When a person feels that using MRRC would enhance their study, he might intend to adopt MR technology in the future. So, it is appropriate to test perceived usefulness with intention to adopt MR technology.

Perceived ease of use is one of the major behavioural beliefs influencing user intention towards technology acceptance [9]. If MRRC is easy to use and the user feels comfortable, then the teaching and learning performance might be enhanced. We would like to test perceived ease of use with perceived usefulness of MRRC and also intention to use MRRC in the future. We also want to know whether ease of use of MRRC would affect respondents' enjoyment. Table 2 below defines the constructs used to determine users' perception and acceptance towards MR technology.

Table 2. Construct Definition

\begin{tabular}{ll} 
Context & Extended Constructs \\
\hline Personal & The willingness of an individual to try out \\
any new information technology [27]. \\
Personal Innovativeness is used to measure \\
the individual traits.
\end{tabular}

There are six hypotheses in this study. The hypotheses were formed according to the extended TAM that we proposed.

H1: Personal innovativeness is positively related to perceive ease of use of MR system.

$\mathrm{H}$ 2: Perceived ease of use is positively related to perceive usefulness of the MR system.

H 3: Perceived ease of use is positively related to perceive enjoyment.

$\mathrm{H}$ 4: Perceived ease of use is positively related to intention to use MR system. 
Volume XII, No. 1, pp. 194-205, 2011

H 5: Perceived enjoyment is positively related to intention to use MR system.

H 6: Perceived usefulness is positively related to intention to use MR system.

\section{METHODOLOGY}

\section{Objectives}

We have developed MRRC and tested it to users in order to answer the following research questions:

- What are the causal relationships between the constructs?

- Which construct(s) affect(s) the intention to use of the MRRC?

\section{System Overview}

The Mixed Reality Regenerative Concept (MRRC) was developed using mixed reality technology to give the Biomedical Science students the exposure on regenerative concept and tissue engineering. Regenerative concept involve three-dimensional, invisible, temporal, and few observable real-life metaphors. This MRRC prototype consists of four topics: The Natural World, Regenerative Medicine, Science of Tissue Engineering, and Tissue Engineering Lab.

- $\quad$ The Natural World - This topic introduces the concept of tissue engineering by exposing the innate ability of lower life forms such as starfish to regenerate lost parts and limited ability in human.

- $\quad$ Regenerative Medicine - This topic explains the needs of regenerative medicine.

- $\quad$ Science of Tissue Engineering - This topic explains the basic concept of tissue engineering and the needs for tissue engineering.

- $\quad$ Tissue Engineering Lab - This topic explains and gives the students the experience on basic process of tissue engineering in the laboratory.

MRRC integrates some components of the situated learning as a model of instruction. Situated learning emphasises on the authentic contexts and activities [3][17]. MRRC combines the real and virtual environments and is supported by $3 \mathrm{D}$ graphics, animation, text, and music. As users navigate the system, they can experience with nine MR environments. MRRC uses markers as tangible interfaces that serve as physical handlers in interacting with virtual object in MR environments. The advantage of tangible interfaces is that they do not require any special purpose of input device and thus they provide an intuitive and seamless interaction with digital and physical objects. Some scenes in MRRC application are shown in the following figures. Figure 3 shows the 3D virtual tissue engineering laboratory where users can explore. In Figure 4, users can see hold and observe starfish regenerate it's arm. By choosing the specific key, users can view the different layers of skin as shown in Figure 5. Users can hold the virtual petri dish to observe how cells proliferate as shown in Figure 6.

Figure 3. Virtual Laboratory

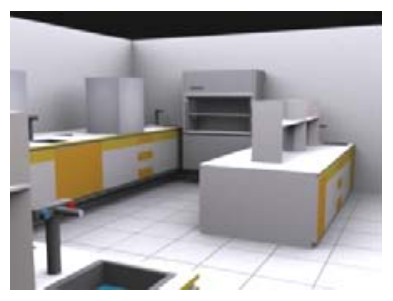

Figure 4. Starfish Regenerate Arm

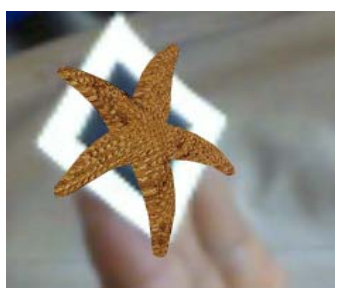

Figure 5. Holding a virtual skin

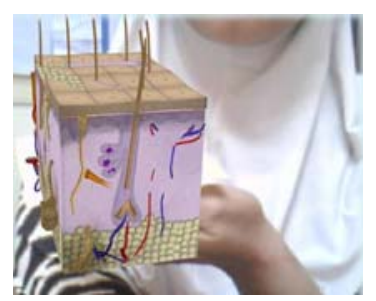

Figure 6. Observe cells proliferate

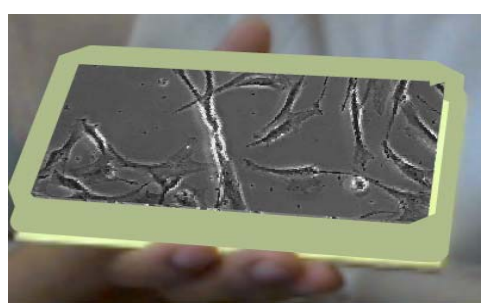




\section{Issues in Information Systems \\ Volume XII, No. 1, pp. 194-205, 2011}

\section{Participants}

This study was conducted at one public university. The participants consisted of 37 volunteers who were from the $2^{\text {nd }}$ and $3^{\text {rd }}$ year Biomedical Science students. Fifteen of the respondents were male $(40 \%)$ and twenty two were female (60\%).

\section{Procedure}

The respondents were never exposed to the MRRC system. This study followed the data collection technique by Oded [23] and Teng et al. [38] where the data were collected immediately after the introduction of the new system and before the users got to use it on a regular basis. The whole study was divided into three sessions: demonstration, brief hands-on, and task-oriented. In the demonstration session, the respondents were explained on the MR concepts and briefly explained on the system. Then, they simply played around with the system. In task-oriented interaction session, a list of tasks was given where the respondents were required to complete. After they had finished the interaction session, the respondents were asked to answer the questionnaires that also included the open-ended comments. Time was taken on completing the task and answering the questionnaires.

\section{Instrument}

In order to achieve the objectives, we develop a set of questionnaire that consisted of 22 items to measure respondents' perception and acceptance towards the prototype system. The questionnaire consisted of five constructs: Personal Innovativeness, Perceived Enjoyment, Perceived Usefulness, Perceived Ease of Use, and Intention to Use. Items in each construct were measured in five-point Likert scale ("Strongly disagree”, "Disagree”, "Not sure”, "Disagree”, "Strongly disagree”).

The items for Personal Innovativeness in IT were adopted from Agarwal \& Prasad [27] while the items for Enjoyment were developed from Venkatesh et al. [36]. The items for Perceived Ease of Use, Perceived Usefulness, and Intention to Use were adopted from the study by Davis [9] that has been validated in numerous studies.

\section{Constructs Reliability}

\section{RESULTS}

The task-oriented session and the questionnaire were completed by 37 participants. We used Cronbach's alpha to test the reliability of the 22 items in five constructs as shown in Table 3.

Table 3. Constructs Reliability

\begin{tabular}{lll} 
Constructs & Items & $\begin{array}{l}\text { Cronbach's } \\
\text { Alpha }\end{array}$ \\
\hline $\begin{array}{l}\text { Personal } \\
\text { Innovativeness }\end{array}$ & 4 & .704 \\
Enjoyment & 6 & .881 \\
Usefulness & 4 & .789 \\
Ease of use & 4 & .809 \\
$\begin{array}{l}\text { Intention to } \\
\text { use }\end{array}$ & 4 & .919
\end{tabular}

These all five factors showed high reliability values, which are above 0.7.In previous research by [11], reliability coefficient for Personal Innovativeness is 0.83 while the reliability coefficient obtained in this study is a little bit lower, which is 0.70 in our sample. For Perceived Enjoyment, we got the same reliability coefficient with Chesney [6], which is 0.88 in our sample. For comparison, we used the reliability coefficient by [37] to measure Perceived 


\section{Issues in Information Systems}

Volume XII, No. 1, pp. 194-205, 2011

Usefulness, Perceived Ease of Use, and Intention to Use constructs. Perceived Usefulness construct was measured with the four- item scale with a reliability coefficient of 0.89 by [37] and of 0.79 in our sample. Perceived Ease of Use construct showed Cronbach's alpha of 0.87 by [37] and of 0.809 in our sample. Intention to Use construct showed reliability coefficient of 0.86 by [37] and of 0.92 in our sample.

Overall, the internal consistency of reliability coefficients for research constructs in this study is well-accepted since the values are between 0.65 and 0.95 [8]. Because the size of respondents was quite small, which is less than 50, thus this study did not conduct factors analysis on each item. Small sample size may affect the factor analysis by making the solution unstable: addition of more data may cause the variables to switch from one factor to another [13].

\section{Personal Background}

Table 4 shows the respondents' profile. Majority of the respondents used the computer intensively in their daily activities (mean value of 3.76 on a 4-point Likert scale). All of the respondents played computer games. About 38\% of the respondents played computer games almost every day, and $22 \%$ of the respondents frequently played games, but majority of the respondents did not frequently play game (mean value 2.46). In terms of VR and AR, the respondents were still not familiar, where the mean values are 2.14 and 1.57, respectively. Almost half of the respondents had never heard of AR or MR.

Table 4. Profile of Respondents

\begin{tabular}{lllll} 
Measure & Item & \% & Mean & Std.dev \\
\hline Gender & Male & 40 & & \\
& Female & 60 & & \\
Frequency & Once a while & & & \\
using & Once a week & & & \\
computer & Frequent & 24 & & \\
& Everyday & 76 & & \\
& & & 3.76 & .44 \\
Frequency & Once a while & 40 & & \\
playing & Once a week & 11 & & \\
games & Frequent & 11 & & \\
& Everyday & 38 & & \\
Knowledge & Not at all & 11 & & \\
about & Everheard & 65 & & \\
VR & A few & 24 & & \\
& & & 2.14 & .58 \\
Knowledge & Not at all & 48 & & \\
about & Everheard & 46 & & \\
AR/MR & A few & 6 & & \\
& & & 1.57 & .603
\end{tabular}

Table 5 shows the descriptive analysis on each contructs. Construct perceived usefulness got the highest average score compared with perceived enjoyment and perceived ease of use.

Table 5. Descriptive Analysis

\begin{tabular}{lcc} 
Constructs & Mean & Std.dev \\
\hline Personal innovativeness & 4.29 & 0.54 \\
Perceived enjoyment & 4.38 & 0.53 \\
Perceived ease of use & 4.37 & 0.60 \\
Perceived usefulness & 4.57 & 0.50 \\
Intention to use & 4.52 & 0.56
\end{tabular}


Volume XII, No. 1, pp. 194-205, 2011

In this study, we used the Spearman's Rank correlation coefficient to test the six hypotheses and summarise the strength and direction (negative or positive) of a relationship between two variables. Table 6 shows the intercorrelation between variables.

Table 6. Intercorrelation between variables $(\mathrm{N}=37)$

\begin{tabular}{|c|c|c|c|c|}
\hline Variables & 2 & 3 & 4 & 5 \\
\hline $\begin{array}{l}1 . \\
\text { Innovativeness }\end{array}$ & $.486^{* *}$ & $.612 * *$ & $.367 *$ & .100 \\
\hline 2. Enjoyment & & $.710 * *$ & $.858^{* *}$ & $.492 * *$ \\
\hline 3. Ease of Use & & &.$\underline{745 * *}$ &.$\underline{564 * *}$ \\
\hline 4. Usefulness & & & & $.703 * *$ \\
\hline 5. Intention to & & & & \\
\hline Use & & & & \\
\hline
\end{tabular}

Note : ${ }^{* *} \mathrm{p}<0.01,{ }^{*} \mathrm{p}<0.05$

The results in Table 6 show that all of the hypotheses were accepted and positively correlated between all the variables. There are highly significant results between Perceived ease of use and Perceived usefulness $(\mathrm{r}=0.745$, $\mathrm{p}<0.05)$, Perceived Ease of Use and Enjoyment $(\mathrm{r}=710, \mathrm{p}<0.05)$, and also between Perceived Usefulness and Intention to Use $(\mathrm{r}=0.703, \mathrm{p}<0.05)$.

The scores also reveal a moderate significant result between Personal Innovativeness and Perceived Ease of Use $(\mathrm{r}=0.612, \mathrm{p}<0.001)$, and between Perceived Ease of Use and Intention to Use $(\mathrm{r}=.564, \mathrm{p}<0.05)$. However, there is a weak correlation between Enjoyment and Intention to Use $(r=.492, \mathrm{p}<0.02)$.

\section{DISCUSSION AND CONCLUSIONS}

In this study, we have revealed the users' acceptance towards the mixed reality application. Even though the respondents from 37 Biomedical Science students have never had any experience on the MR system, they showed a strong willingness to use the MR application in the future. To determine the users' acceptance towards MRRC, we have proposed five constructs that combine the basic TAM model (Perceived usefulness, Perceived ease of use, and Intention to Use), personal traits (Personal innovativeness) and experience on using MR (Perceived enjoyment).

Results from simple correlation analysis accepted all the six hypotheses. There is a positive correlation between Personal Innovativeness and Perceived ease of use. This is true because the more innovative the respondents are, the more they are willing to experience with new technology and they find it easier to use MR system even though they have never experienced it before. This result is supported by previous research [12][14]. Other factors might influence the result because the system design was quite simple and it used a fiducial marker with simple interactivity. The results also reveal that Perceived ease of use is positively related to Perceived usefulness of the MR system. This indicates that when respondents find that the system is easy to use, they will perceive it as useful in their study. This result is supported by previous research [9][36].

There is a positive correlation between Perceived ease of use and Perceived enjoyment. This means that the system that is easy to be used will increase participants' enjoyment during the interaction session. This result is supported by previous research [6][36].

The results also show that Perceived ease of use is positively related to Intention to use the MR system. When respondents find that system is easy to use, they might want to use it in the future. 
Volume XII, No. 1, pp. 194-205, 2011

Perceived enjoyment is also positively related to Intention to use. We can assume that the system that is enjoyable to be used might attract users' intention in the future.

The study also indicates that Perceived usefulness is positively related to Intention to use. This is absolutely true since the system is useful in the respondents' study and thus they might want to use in the future.

There are a few limitations in this study. First, there was small number of respondents, which were only 37. Future works should repeat the study with more respondents with gender and various races of respondents. Second, the results only reveal the descriptive and simple correlation analysis of the testing. Further advance regression analysis should be performed to assess the association between variables. Since the respondents were from the same university, future works should conduct the testing in a few universities to get the results from various backgrounds.

\section{REFERENCES}

1. Brett E. Shelton, Nicholas R.Hedley (2004) Exploring a cognitive basis for learning spatial relationships with augmented reality. Tech., Inst., Cognition and Learning, Vol(1), 323-357.

2. Brian Goldiez, Mark A. Livingston (2004). Proceedings for the Army Science Conference (24th) Available: www.dtic.mil/cgi-bin/GetTRDoc?Location=U2\&doc=GetTRDoc.pdf\&AD=ADA433480.

3. Brown, J.S., Collins, A. \& Duguid, S. (1989). Situated cognition and the culture of learning. Educational Researcher, 18(1), 32-42.

4. Caudell T. Mizell D. (1992). Augmented Reality: An application of heads-up display technology to manual manufacturing processes. Proceedings of the TwentyFifth Hawaii International Conference on System Sciences (1992), Vol 2, 659-669.

5. Chris Dede (2005). Planning for Neomillennial Learning Styles: Implications for Investments in Technology and Faculty. EDUCAUSE2005. Available: http://www.educause.edu/ir/library/pdf/pub71010.pdf

6. Chesney Thomas (2006). An Acceptance Model For Useful and Fun Information System. Journal on Humans In ICT Environment, 2(2), 225-235.

7. Chin-Lung Hsu, Hsi-Peng Lu (2004). Why do people play on-line games? An extended TAM with social influences and flow experience. Information \& Management 41 (2004), 853-868.

8. Chua Yan Piaw, Asas Statistik Penyelidikan, Buku 2, pg 84, Mc Graw Hill .

9. Davis F. D. (1989). Perceived usefulness, perceived ease of use, and user acceptance of information technology. MIS Quarterly 13(3), 319-340.

10. Davis F. D. (1993). User Acceptance of Information Technology: System Characteristics, User Perceptions and Behavioural Impacts. International Journal Human-Machine Studies (59), 475-487.

11. Erick M,. Jeroen J.L. (2006). The acceptance and use of a virtual learning environment in China.Computers \& Education 50(2008), 838-852.

12. Farzana P. Ainin S. Technology Complexity, Personal Innovativeness and Intention to use wireless internet using mobile device in malaysia. International Review of Business Research Papers. 4(5), 1-10.

13. Guadagnoli, Edward and Wayne F. Velicer (1988). Relation of sample size to the stability of component patterns. Psychological Bulletin 103(2), 265-275.

14. Hae Young Lee, Hailin Qu, Yoo Shin Kim (2007). A study of the impact of personal innovativeness on online travel shopping behavior - A case study of Korean travelers. Tourism Management 28(2007), 886-897.

15. Jeroen Bourgonjon, Martin Valcke, Ronald Soetaert, Tammy Schellens (2009).Students' Perceptions about the use of video games in the classroom. Journal Computers\& Education (54), 1145-1156.

16. James J.W. Lin, Donald E Parker(2007). User Experience Modelling and Enhancement for Virtual Environments that Employ Wide-Field Displays. LNCS Vol 4561, 423-433. 
Volume XII, No. 1, pp. 194-205, 2011

17. Lave, J., \& Wenger, E. (1990). Situated Learning: Legitimate Periperal Participation. Cambridge, UK: Cambridge University Press.

18. Lisa Seymour, Wadzanai Makanya, Simon Berrangé (2007). End-Users' Acceptance of Enterprise Resource Planning Systems: An Investigation of Antecedents. In Proceedings of the 6th Annual ISOnEworld Conference, April 11-13, 2007.

19. Louho, R., Kallioja, M.,\& Oittinen, P. (2006). Factors Affecting the Use of Hybrid Media Applications. Graphic Arts in Finland, 35(3), 11-21.

20. Manon Bertrand, Stéphane Bouchard (2008). Applyinh the technology acceptance Model to VR With People Who Are Favorable To Its Use. Journal of Cyber Therapy \& Rehabilition 1(2).

21. Marjaana Träskbäck, Michael Haller Träskbäck. (2004). Mixed Reality Training Application for an Oil Refinery: User Requirements.Virtual Reality Continuum and its applications in Industry (VRCAI04), NTU, Singapore (June 2004).

22. Marcel Heerink, Ben Krose, Bob Wielinga, Vanessa Evers (2008). Enjoyment, Intention to Use and Actual Use of . a Conversional Robot by Elderly People. Proceeding of HRI (2008).

23. Oded Nov, Chen Ye(2008). Personality and technology acceptance : Personal innovativeness in IT, openness and resistance to change(2008). Proceedings of the 41st Hawaii International Conference on System Sciences.

24. O’Cass, A., \& Fenech, T. (2003). Web retailing adoption: Exploring the nature of Internet users web retailing behavior. Journal of Retailing and Consumer Services, 10(2), 81-94.

25. Paul Milgram, Fumio Kishino (1994). Taxonomy of Mixed Reality Visual Displays. IECE Trans. on Information and Systems (Special Issue on Networked Reality), E77-D(12), 1321-1329.

26. Paul Legris, John Ingham, Pierre Collerette. Why do people use information technology? A critical review of the technology acceptance model? Information and Management(40), 191-204.

27. Ritu Agarwal, Jayesh Prasad (1998). A Conceptual and Operational Definition of Personal Innovativeness in the Domain of Information Technology. Information Systems Research, 9(2), 204-215.

28. Rogers, E. M. (1995). Diffusion of Innovations (4th ed). New York: The Free Press.

29. Sun H. and Zhang. P. Causal Relationships berween Perceived Enjoyment and Perceived Ease of Use: An Alternative Approach. Journal of Association for Information Systems. 7(9), 618-645.

30. Ronald T. Azuma (1997). A Survey of Augmented Reality. Presence: Teleoperators and Virtual Environments, 6(4), 355-385. Available: www.ijvr.org/issues/issue2-2010/paper1\%20.pdf.

31. Ronald Azuma, Yohan Baillot, Reinhold Behringer, Steven Feiner, Simon Julier, Blair MacIntyre. Recent Advances in Augmented Reality. Computer Graphics and Applications, IEEE, Vol. 21, No. 6. (2001), 34-47.

32. Sonny E. Kirkley, Jamie R. Kirkley (2005). Creating Next Generation Blended Learning Environments Using Mixed Reality, Video Games and Simulations. TechTrends, 49(3), 42-53.

33. Susanna Nilsson, Björn Johansson (2008). Acceptance of Augmented Reality Instructions in a Real Work Setting. Proceeding CHI Extended Abstracts, 2025-2032.

34. Sutherland I. (1965). The Ultimate Display. Proceeding of IFIP ‘65, 506-508.

35. Tomotsugu Kondo (2005). Augmented Learning Environment using Mixed Reality Technology. World Conference on E-Learning in Corporate, Government, Healthcare, and Higher Education (ELEARN) 2006, 8387). Available : www.editlib.org/f/23664.

36. Viswanath Venkatesh, Michael G. Morris, Gordon B. Davis, Fred D. Davis (2003). User Acceptance of Information Technology: Toward a Unified View. MIS Quarterly, 27( 3), 425-478.

37. William R.King, Jun He (2006). A meta-analysis of the technology acceptance model. Information \& Management, 43(6), 740-755. 


\section{Issues in Information Systems}

Volume XII, No. 1, pp. 194-205, 2011

38. Yin-Leng Theng, Charissa Lim Mei-Ling, Wei Liu, Adrian Cheok. Mixed Reality Systems for Learning. Proceedings of International Conference on Virtual Reality, 728-737. 